\title{
«FÉTICHISME DE LA LOI, SÉPARATION DES POUVOIRS ET GOUVERNEMENT DES JUGES". TRES IDEAS-FUERZA PARA EL RECHAZO DEL CONTROL JURISDICCIONAL DE LA CONSTITUCIONALIDAD DE LAS LEYES EN FRANCIA (1789-1958)*
}

\author{
FRANCISCO FERNÁNDEZ SEGADO \\ Catedrático de Derecho Constitucional. \\ Universidad Complutense de Madrid
}

\section{SUMARIO}

I. Introducción.

II. El dogma rousseauniano de la soberanía parlamentaria y su radical contradicción con la "judicial review".

III. El fetichismo de la ley.

IV. La rigidez del principio de separación de poderes y el rol secundario del Juez.

V. El mito del "gobierno de los jueces".

VI. El rechazo de toda capacidad de creación de Derecho por parte del Juez.

VII. La difuminación de la distinción entre el poder constituyente y el poder legislativo constituido.

VIII. La devaluación y fragilidad de las Constituciones.

IX. Recapitulación final.

* Este trabajo integra la introducción de un capítulo de un libro que bajo el título de "La justicia constitucional. Francia. Estados Unidos. Europa. América Latina. España" será publicado por el autor en enero de 2008, en la Editorial Dykinson. 


\section{INTRODUCCIÓN}

El estudio de la justicia constitucional en Francia tiene que partir de una premisa indiscutible: el endémico, y aún diríamos con Neuborne que vigoroso ${ }^{1}$, rechazo del control judicial de la constitucionalidad de las leyes. A su vez, la inexistencia de un control judicial se ha traducido en la ausencia de mecanismos eficientes de aseguramiento de la supremacía constitucional. Como comienza señalando en una obra ya clásica Luchaire ${ }^{2}$, durante 169 años, el Derecho público francés no ha podido aportar más que débiles respuestas a la cuestión de cómo asegurar la supremacía de la Constitución, aunque ciertamente la hoy vigente Constitución de 1958 testimonia un espíritu diferente, que se ha visto acentuado, por mor de una evolución en verdad sorprendente, por el "activismo judicial" del Conseil Constitutionnel.

La constante histórica enunciada es a su vez tributaria de la muy acentuada peculiaridad del pensamiento constitucional francés, construido históricamente sobre la base de una combinación de las ideas de Rousseau y Montesquieu ${ }^{3}$.

\section{EL DOGMA ROUSSEAUNIANO DE LA SOBERANÍA PARLAMENTARIA Y SU RADICAL CONTRADICCIÓN CON LA "JUDICIAL REVIEW"}

Es a Rousseau a quien se debe no el descubrimiento de la teoría de la soberanía popular, como bien señalara Carré de Malberg ${ }^{4}$, sino su más nítida formulación teórica. Su tesis, como es sobradamente conocido, encuentra su sustento en la idea del contrato social, en el que se asienta la sociedad y el Estado 5 . El objeto de tal contrato no es tan sólo producir un cuerpo moral y co-

1 "France - afirma Neuborne-, a nation that has until recently, vigorously rejected substantive judicial review". Burt NEUBORNE: "Judicial Review and separation of powers in France and the United States", en New York University Law Review, vol. 87, núm. 3, june 1982, pp. 363 y ss.; en concreto, p. 377.

2 François LUCHAIRE: Le Conseil Constitutionnel, Economica, París, 1980, p. 1.

3 Es ésta una idea absolutamente compartida por la doctrina, particularísimamente en el pasado siglo, desde la más reciente hasta la más alejada en el tiempo. Valgan como ejemplos, François LUCHAIRE: "El Consejo Constitucional Francés", en el colectivo Tribunales Constitucionales Europeos y Derechos Fundamentales, CEC, Madrid, 1984, pp. 55 y ss.; en concreto, pp. 55-56. Y en los inicios del siglo xx, P. FRÉDÉRIC-SIMON: "Le gouvernement de M. Thiers d'après la Résolution du 17 février 1871", en Revue du Droit Public, 1910, pp. 209 y ss.; en concreto, p. 215. Para este autor, al'histoire constitutionnelle de la France est celle de la lutte de deux dogmes. En face de la théorie de la séparation des pouvoirs exposée par Montesquieu, s'est élevé dès le xviIIè siècle, le principe de la souveraineté populaire inaliénable et indivisible, dont Rousseau s'était fait le champion".

4 R. CARRÉ DE MALBERG: Contribution à la Théorie Générale de l'État, tome II, Recueil Sirey, Paris, 1922, p. 153.

5 "Encontrar una forma de asociación que defienda y proteja de toda fuerza común a la persona y a los bienes de cada asociado, y por virtud de la cual cada uno, uniéndose a todos, no obe- 
lectivo, sino también y esencialmente, crear, en el seno de la sociedad, una autoridad pública superior a los individuos. Cada contratante "pone en común su persona y todo su poder bajo la suprema dirección de la voluntad general", que de esta forma se convierte en soberana. Asimismo, en cuanto cada contratante recibe a los demás "como parte indivisible del todo", la voluntad general no es sino la resultante de las voluntades individuales ${ }^{6}$. De esta forma, los asociados "toman colectivamente el nombre de pueblo, y se llaman en particular ciudadanos, en cuanto son participantes de la autoridad soberana ${ }^{7}$. Si mediante el pacto social se da existencia y vida al cuerpo político, es la legislación la que va a otorgar al mismo el movimiento y la voluntad. En cuanto que actos de la voluntad general", no hay que preguntar a quién corresponde hacer las leyes; éstas sólo pueden emanar del pueblo o de sus representantes.

A partir de aquí, durante mucho tiempo se considerará como un principio absoluto que la ley, en cuanto mandato dado por el poder soberano, no puede emanar más que del Parlamento, el único que por representación ejerce las diversas prerrogativas de la soberanía nacional. Ello encontrará recepción en la Constitución francesa de 3 de septiembre de 1791, en cuyo artículo $3 .^{\circ}$ del Preámbulo del Título III se dispone: «Le Pouvoir législatif est délégué à une Assemblée Nationale composée de représentants temporaires, librement élus par le peuple.... ${ }^{8}$.

Cuanto se ha expuesto justifica que el Derecho público francés se haya inspirado de modo más o menos consciente en estos dos principios: 1) la ley, en cuanto expresión de la voluntad general, es la manifestación misma de la soberanía, y 2) el Parlamento expresa de modo directo la voluntad general. De la convergencia de ambos principios dimana la idea de que el poder legislativo "est d'une essence et d'une majesté particulières, qu'il ne se définit point comme une compétence parmi d'autres, mais comme l'expression même de la souverainetén"?

Una tal visión del poder legislativo supondrá, como con singular clarividencia explicara Carré de Malberg ${ }^{10}$, la desaparición de una de las principales utilidades de la diferenciación del poder constituyente respecto de los poderes constituidos. "Le but pratique de la distinction, c'est, en effet, de limiter la puis-

dezca sino a sí mismo y quede tan libre como antes". Tal es el problema fundamental, al cual da solución el contrato social." Juan Jacobo ROUSSEAU: Contrato Social, Espasa-Calpe, Madrid, 1975, Capítulo VI del Libro primero.

6 "La voluntad constante de todos los miembros del Estado es la voluntad general; por ella son ciudadanos y libres". J. J. ROUSSEAU: Contrato Social, op. cit., Capítulo II del Libro cuarto.

7 Ibidem, Capítulo VI del Libro primero.

8 En todas nuestras referencias a los textos constitucionales franceses, salvo puntualización expresa en contrario, seguimos la obra de Maurice DUVERGER: Constitutions et documents politiques, 6. ${ }^{a}$ ed., Presses Universitaires de France, París, 1957.

9 Georges VEDEL: Droit Constitutionnel, Sirey, 2è tirage, Paris, 1984, p. 477.

10 R. CARRÉ DE MALBERG: Contribution..., tome II, op. cit., pp. 514-515. Puede verse asimismo la versión española de esta obra bajo el título Teoría General del Estado, Facultad de Derecho de la UNAM/FCE, 1. ${ }^{a}$ reimpr. de la 2. ${ }^{a}$ ed. en español, México, 2000, pp. 1187-1188. 
sance de l'organe législastif, et notamment de la limiter en ce qui concerne les droits individuels des particuliers, en ce sens que ces droits, une fois déterminés et garantis par l'acte constitutionnel, ne peuvent plus être restreints ni retouchés par le législateur ordinaire». Es decir, la idea fundamental que subyace en la diferenciación de un poder constituyente superior al poder legislativo, que no es otra sino la de que en un Estado soberano puede establecerse y reservarse jurídicamente, en beneficio de los ciudadanos, una esfera de libertad individual que se sustrae de esta forma a la libre disponibilidad de los poderes constituidos, se convierte en un imposible. Como una vez más advierte el Profesor de Estrasburgo, la teoría del contrato social excluye completamente el concepto de derechos individuales intangibles frente al legislador, y ello, al menos, por dos razones: la primera, por la completa absorción del individuo por la comunidad, pues como dice Rousseau ${ }^{11}$, las cláusulas del contrato social debidamente entendidas "se reducen todas a una sola, a saber: la enajenación total de cada asociado con todos sus derechos a toda la comunidad", y ya desde este punto de vista deja de concebirse la noción de un derecho individual propiamente dicho. La segunda, porque aunque se supusiera, de hecho, al individuo provisto de semejante derecho por la ley del Estado, este derecho apenas si tendría valor y la seguridad de los particulares sería nula, ya que en todo caso la reglamentación de los derechos individuales y también su modificación extensiva o restrictiva dependen siempre del soberano, que en la teoría rousseauniana no es otro que el legislador. De esta forma, el Parlamento, en cuanto voz de la soberanía popular, iba a ser visto como el mejor garante de los derechos. Estos, sin embargo, no presuponían restricción alguna al poder soberano del Estado, ni por tanto al del Parlamento, cuya actuación quedaba al margen de todo límite. Como advertiría Duguit $^{12}$, la originalidad de Rousseau, como años después la de Hegel, consiste en el esfuerzo hecho por demostrar que a pesar de este poder omnímodo del Estado, el hombre queda libre y conserva la plenitud de su autonomía.

Innecesario es decir que el control judicial de la constitucionalidad de las leyes chocaba de modo frontal con esta visión de la soberanía parlamentaria "in edizione evoluta del princeps legibus solutus", como la tilda Esposito ${ }^{13}$, juicio que ya había sostenido tiempo atrás Duguit al significar que la doctrina de la soberanía rousseauniana había sido siempre, en la teoría y en la práctica, una doctrina de absolutismo ${ }^{14}$. Si se tiene en cuenta que la vinculación a las ideas de

11 J. J. ROUSSEAU: Contrato Social, op. cit., Capítulo VI del Libro primero.

12 Léon DUGUIT: "Jean-Jacques Rousseau, Kant et Hegel", en Revue du Droit Public, tome trente-cinquième, 1918, pp. 173 y ss.; en concreto, p. 179.

13 Enrico ESPOSITO: "Il Consiglio Costituzionale in Francia", en Rivista Trimestrale di Diritto Pubblico, año XXII, 1972, pp. 351 y ss.; en concreto, p. 414.

14 Léon DUGUIT: Las transformaciones del Derecho Público (traducción y estudio preliminar de Adofo Posada y Ramón Jaén), Francisco Beltrán, Madrid, 1913, p. 88. Duguit, en su amplia obra, responsabilizará a Rousseau de todas las ficciones democráticas obra de aquellas doctrinas, francesa o alemana, de la soberanía que han visto la misma con un poder puramente voluntarista. En tal sentido se pronuncia Evelyne PISIER: "Léon Duguit et le contrôle de la constitutionnalité des lois", en 
Rousseau siempre ha permanecido presente en Francia, se puede comprender que la judicial review no haya sido nunca realmente aceptada en ese país ${ }^{15}$. Y ello ha sido así incluso en épocas en que la pervivencia del dogma de la soberanía parlamentaria, de resultas del continuo cambio legislativo, estimulado por las pasiones electorales, ha llegado a ser, como constatara Hauriou ${ }^{16}$, una amenaza y un peligro para la libertad. De la pervivencia de este dogma, que resurge periódicamente de sus cenizas en nuestro vecino país, aún en momentos y circunstancias que parecen sugerir su definitiva desaparición, nos da cumplido testimonio Favoreu, que en 1982, comentando las Decisiones del Conseil constitutionnel en torno al tema de las nacionalizaciones ${ }^{17}$ llevadas a cabo bajo la égida del Presidente Mitterrand, constataba con sorpresa ${ }^{18}$ que aunque se podía pensar que la cuestión de la sumisión del legislador al principio de constitucionalidad era algo finiquitado, que había dejado de plantearse como cuestión problemática desde los años setenta, la misma reverdecía en base a la, a nuestro juicio, obsoleta argumentación de que la voluntad popular expresada en las elecciones presidenciales y parlamentarias de mayo/junio de 1981, no podía conocer límites, al menos respecto a las reformas consideradas esenciales por la nueva mayoría socialista. El propio primer secretario del Partido socialista francés declararía: «jamais les grands courants de réforme ne se sont laissés arrêtés par une Cour suprême quelle qu'elle soit", en una alusión que obviamente tenía como telón de fondo el conflicto entre la Supreme Court norteamericana y el Presidente Roosevelt surgido con ocasión del New Deal ${ }^{19}$.

\section{EL FETICHISMO DE LA LEY}

En el sistema del Derecho público francés fundado sobre la noción de soberanía, todo el mundo iba a mostrarse de acuerdo en el reconocimiento de

Droit, institutions et systèmes politiques (Mélanges en hommage à Maurice Duverger), Presses Universitaires de France, París, 1987, pp. 189 y ss.; en concreto, p. 191.

15 En igual sentido, Mauro CAPPELLETTI y John Clarke ADAMS: "Judicial Review of Legislation: European Antecedents and Adaptations", en Harvard Law Review, vol. 79, 1965-1966, pp. 1207 y ss.; en concreto, p. 1212.

16 Maurice HAURIOU: Principios de Derecho público y constitucional, traducción y estudio preliminar de Carlos Ruiz del Castillo, Instituto Editorial Reus, 2. ${ }^{a}$ ed., Madrid, 1932, pp. 334-335.

17 Nos referimos a las Decisiones 81-132 DC, de 16 de enero de 1982 (Nationalisations I), y 82-139 DC, de 11 de febrero de 1982 (Nationalisations II). Pueden verse en la obra Recueil de jurisprudence constitutionnelle. 1959-1993 (réunies par Louis FAVOREU), Editions Litec, París, 1994, pp. 104 y ss. y 121 y ss., respectivamente.

18 Louis FAVOREU: "Les décisions du Conseil Constitutionnel dans l'affaire des nationalisations", en Revue du Droit Public, 1982, núm. 2, pp. 377 y ss.; en concreto, pp. 399-400 y también pp. 380-381.

19 Aun constituyendo una opinión disidente, como se significaba en el propio rótulo del artículo, la cuestión de la ilimitada soberanía del Parlamento seguía encontrando sus adeptos en los años ochenta. Buen ejemplo de ello lo encontramos en René de LACHARRIÈRE: “Opinion dissidente", en Pouvoirs, núm. 13, 1980, pp. 133 y ss. Este autor se formulaba el siguiente interrogante: 
que la ley era la manifestación por excelencia de la soberanía. El propio Rousseau lo iba a admitir en diversas ocasiones. Recordemos que para el gran pensador ginebrino el hombre no era libre más que cuando pasivamente quedaba sometido a la voluntad general ${ }^{20}$. La omnipotencia del Estado hace libre al individuo. Ahora bien, sólo el acto de soberanía se impone sin reserva alguna a las voluntades individuales, y ese acto de soberanía no es sino la $l e y^{21}$. En cuanto ella es la manifestación externa de la voluntad general, Rousseau considera perfectamente lógico y compatible que se sea libre y se esté al unísono sometido a la ley ${ }^{22}$. Derivará de este razonamiento, como pondría de relieve Duguit hace casi un $\operatorname{siglo}^{23}$, lo que a veces se ha llamado el "fetichismo de la ley", idea a la que otros se han referido con diversas expresiones: la mística de la $l e y^{24}$, la idolatría de la $l e y^{25}$.. Todo ello no será sino el fruto de una concepción tildada de metafísica ${ }^{26}$, y en todo caso, ficticia e irreal, pero que colocará a la ley en la cumbre del ordenamiento jurídico y, de resultas de ello, al órgano que la elabora, al órgano parlamentario, en una situación dominante respecto de los demás órganos del Estado que se encuentran, en relación al órgano legislativo, en una clara situación de subordinación.

La Revolución consagrará esta concepción, y así, el artículo 6. ${ }^{\circ}$ de la $D e ́-$ claration des Droits de l'Homme et du Citoyen, de 26 de agosto de 1789, se abrirá con la celebérrima afirmación: "La loi est l'expression de la volonté générale". De poco valdrá que un sector importante de la iuspublicística francesa, particularmente en los inicios del pasado siglo, ofrezca indiscutibles argumentos con los que refutar tan venerada concepción. Recordemos, por hacernos eco de algunas de tales opiniones, a Duguit y Jèze, cuyos juicios iban a ser bien parejos. Mientras para el primero ${ }^{27}$ la ley es simplemente la expresión de la voluntad individual de los hombres que la hacen: jefes de Estado y miembros del Parlamento, y fuera de esto, todo lo que se diga no es más que una ficción,

"Comment la volonté nationale peut-elle être liée par une de ses manifestations antérieures, au prétexte que celle-ci a été inscrit dans un document spécial, dénommé Constitution?” (p. 134).

20 "La voluntad constante de todos los miembros del Estado es la voluntad general; por ella son ciudadanos y libres». J. J. ROUSSEAU: Contrato..., op. cit., Capítulo II del Libro cuarto.

21 La soberanía de la ley entrañaría un triple efecto: 1) por su contenido, la ley se caracterizaba como un acto indeterminado; 2) por su ámbito, la ley presentaba el carácter de un acto indefinido, y 3) por su rango, la ley era el acto supremo. Cfr. al efecto, Michel-Henry FABRE: «La loi expression de la souveraineté", en Revue du Droit Public, 1979, núm. 2, pp. 341 y ss.; en concreto, p. 342 .

22 Contrato Social, Capítulo VI del Libro segundo.

23 Léon DUGUIT: Las transformaciones del Derecho público, op. cit., p. 144.

24 Georges VEDEL, en el "Préface" a la obra de Francine BATAILLER, Le Conseil d'État juge constitutionnel, LGDJ, París, 1966, p. I.

25 Paolo PASSAGLIA: "La Giustizia Costituzionale in Francia", en la obra Esperienze di Giustizia Costituzionale, a cura di Jörg LUTHER, Roberto ROMBOLI y Rolando TARCHI, Giappichelli, Torino, 2000, tomo I, pp. 199 y ss.; en concreto, p. 199.

26 Georges BURDEAU: Traité de Science Politique, tome IV (Le statut du pouvoir dans l'État), 2ème édition, LGDJ, París, 1969, p. 376.

27 Léon DUGUIT: Las transformaciones..., op. cit., p. 145. 
para el segundo ${ }^{28}$, "la loi est la manifestation de volonté d'individus investis d'une compétence. Cette compétence est réglée par la loi constitutionnelle et le Droit. Elle doit, comme toute compétence, s'exercer conformément à la loi et au Droit”. En último término, para Jèze, la confección de la ley no será otra cosa que el funcionamiento de un servicio público, el servicio público más importante, el servicio de la legislación.

Las abundantes y cualificadas críticas no harán mella en la concepción expuesta; por el contrario, la misma, con algún matiz, llegará hasta la Quinta República, superando su sexquicentenario. Se propiciará así lo que Hauriou denominaría ${ }^{29}$ un "Estado de Derecho puramente legal", caracterizado por exaltar la ley y abatir al Juez, concepto que en sí mismo, a nuestro modo de ver, no deja de ser equívoco, pues el Estado de Derecho es una noción diferente a la del Estado legal ${ }^{30}$; nos bastará con decir con Rivero que "le caractère absolu de la souveraineté parlementaire fût contraire à la définition de l'État de droit ${ }^{31}$.

No se entendería así por los revolucionarios de 1789, que con una visión de la democracia radical, que propiciaría un régimen asambleario, impreso en las instituciones del período revolucionario, glorificarían la ley, rechazando de raíz todo control judicial ${ }^{32}$. En una democracia jacobina carece de sentido hablar de control judicial de la constitucionalidad de las leyes. Por lo demás, el inmediato pasado, como veremos con algún detenimiento más adelante, propició la inequívoca hostilidad de los revolucionarios frente a los jueces. No en vano habían sido esos mismos jueces, integrantes de los Parlements, los mayores enemigos de todas y cada una de las reformas liberales emprendidas en los años previos a la Revolución, por pequeñas que las mismas fueran. Como diría Cappelletti ${ }^{33}$, «they (the judges) were the fiercest opponents of the Revolution".

Habrá que esperar a la Constitución de 1958 para que se imponga una nueva concepción que deje de lado el fetichismo tradicional de la ley. La propia Constitución pareció arruinar el principio de "la loi, expression de la volonté générale", fundamentalmente por la revolución jurídica que parecía suponer su artículo 37, que atribuía al ámbito reglamentario todas aquellas materias no ex-

28 Gaston JÈZE: "Le contrôle juridictionnel des lois", en Revue du Droit Public, tome XLI, núm. 3, juillet/août/sept. 1924, pp. 399 y ss.; en concreto, p. 401.

29 Maurice HAURIOU: Principios de Derecho público y constitucional, op. cit., p. 346.

30 Cfr. al respecto, Léo HAMON: "L'État de droit et son essence", en Revue Française de Droit constitutionnel, 1990, núm. 4 (número monográfico sobre "L’exception d'inconstitutionnalité"), pp. 699 y ss.; en concreto, p. 703.

31 Jean RIVERO: "Fin d'un absolutisme", en Pouvoirs, núm. 13, 1980 (monográfico sobre "Le Conseil Constitutionnel"), pp. 5 y ss., en concreto, p. 9.

32 "France being the country of government by assembly par excellence the idea of legislative supremacy and the resultant glorification of written norms was here more firmly entrenched that in other countries". En tales términos se expresa Gottfried DIETZE: "America and Europe. Decline and emergence of judicial review", en Virginia Law Review, vol. 44, núm. 8, diciembre 1958, pp. 1233 y ss.; en concreto, p. 1257.

33 Mauro CAPPELLETTI: Judicial Review in the contemporary world, The Bobbs-Merrill Company, Indianapolis/Kansas City/New York, 1971, p. 35. 
presamente reservadas por el artículo 34 a la ley, lo que, como señalaría Vedel ${ }^{34}$, sería visualizado en un primer momento como el establecimiento de la teoría de un "double pouvoir normatif" que atentaba de modo frontal contra la estructura secular que presuponía el mencionado dogma. Sin embargo, el Consejo de Estado, en la Sentencia "Syndicat général des ingénieurs-conseils", de 26 de junio de 1959, dio la espalda a tal teoría. Por lo demás, en una Sentencia de $1985^{35}$, en un obiter dictum que ha sido considerado como uno de los aportes teóricos más importantes de la jurisprudencia constitucional ${ }^{36}$, el Conseil constitutionnel reconducía a su justo término el dogma tantas veces citado al precisar que «la loi (...) n'exprime la volonté générale que dans le respect de la Constitution". Habrían tenido que transcurrir casi dos siglos desde la Revolución para que un órgano jurisdiccional, pues hoy no puede caber duda acerca de esa naturaleza respecto del Conseil, recondujera explícitamente el principio, acomodándolo al principio de primacía de la Constitución.

\section{LA RIGIDEZ DEL PRINCIPIO DE SEPARACIÓN DE PODERES Y EL ROL SECUNDARIO DEL JUEZ}

Otro principio realmente determinante en la evolución del Derecho público francés sería el de la separación de poderes, que resultaría igualmente decisivo en orden a la exclusión de todo control jurisdiccional sobre la ley. "Le principe de la séparation des pouvoirs — afirmaría Duez ${ }^{37}$ — est tourné tout entier contre le pouvoir judiciaire dont on se méfie, parce qu'il est soupçonné d'être hostile à l'ordre de choses nouveau" ${ }^{38}$.

Si la ley era un mandato emanado del poder soberano, tal y como quedaba claro en la teoría rousseauniana, era evidente que la misma no podía provenir más que del Parlamento, el órgano que disponía de dicho poder. En sintonía con ello, el artículo $1 .^{\circ}$ de la sección primera del Capítulo III del Título tercero de la Constitución de 1791, encomendaba en exclusiva al Cuerpo legislativo la

34 Georges VEDEL: "Discontinuité du Droit constitutionnel et continuité du Droit administratif: le rôle du juge", en Mélanges offerts à Marcel Waline (Le juge et le Droit public), tome II, LGDJ, Paris, 1974, pp. 777 y ss.; en concreto, pp. 785-787.

35 Décision 85-197 DC, de 23 de agosto [Évolution de la Nlle-Calédonie(II)], Considérant numéro 27.

36 Dominique ROUSSEAU: "La réforme du 29 octobre 1974 vue en 1994: le "big-bang" de la démocratie constitutionnelle?", en la obra Vingt ans de saisine parlementaire du Conseil Constitutionnel (Association Française des Constitutionnalistes. Journée d'Etudes du 16 mars 1994), Economica/Presses Universitaires d'Aix-Marseille, Paris, 1995, pp. 67 y ss.; en concreto, p. 77.

37 Paul DUEZ: "Le contrôle juridictionnel de la constitutionnalité des lois en France", en $M e ́-$ langes Maurice Hauriou, Recueil Sirey, Paris, 1929, pp. 211 y ss.; en concreto, p. 232.

38 En análoga dirección se manifiestan Cappelletti y Adams, para quienes: "The theory of the separation of powers as exacerbated by Rousseau gave French democratic political theory a matrix into which judicial review could not fit". Mauro CAPPELLETTI y John Clarke ADAMS: "Judicial Review of Legislation...", op. cit., p. 1211. 
aprobación de las leyes ${ }^{39}$. Y complementando tal previsión, el artículo $6 .^{\circ}$ de la sección primera del Capítulo IV del mismo Título vedaba explícitamente al poder ejecutivo dictar una ley ${ }^{40}$. En el fondo de todo ello nos encontramos, como dijera Duguit ${ }^{41}$, con el principio de la separación de poderes, al que se iba a dar un diseño draconiano, absoluto, como el propio autor expondría en otro lugar ${ }^{42}$, y del que constituirían manifestaciones significativas: la negación al Rey, depositario del poder ejecutivo, de lo que hoy llamaríamos la potestad reglamentaria, como asimismo de toda iniciativa legislativa; también el rol absolutamente secundario de los jueces encontraría su razón de ser, como más adelante expondremos, en el propio principio.

No debe extrañar especialmente el fuerte influjo de Montesquieu por cuanto en los orígenes del movimiento revolucionario está mucho más presente el pensamiento de Montesquieu que el de Rousseau. Nada era más extraño a los Estados Generales reunidos en 1789 que la idea de una República, contraria a los deseos del conjunto del país. Lo que reclamaban en realidad los Cahiers, diría Vedel ${ }^{43}$, era un gobierno inspirado en Montesquieu, no en Rousseau, esto es, una monarquía en la que el poder del Rey fuera limitado por los representantes de la nación, en definitiva, una monarquía representativa ${ }^{44}$. Es a la construcción de tal modelo hacia lo que orientarán su tarea les États Généraux transformados en Asamblea Nacional. Ello nos conduce directamente al pensamiento de Charles-Louis de Secondat, sobre el que vamos a detenernos brevemente.

El barón de la Brède y de Montesquieu (1689-1755) había nacido en el seno de una familia estrechamente vinculada con el mundo de la toga, de antiguos juges des Parlements. Ya en 1713, tras la muerte de su padre, era elegido consejero del Parlement de Bordeaux y tres años más tarde, de resultas del fallecimiento de su tío el barón de Montesquieu, heredaba no sólo el título nobiliario, sino también la presidencia — président à mortier - del mencionado Parlement. Ello nos pone sobre aviso acerca de la enorme familiaridad, del gran conocimiento, que Montesquieu tendría de los órganos jurisdiccionales de su tiempo. No cabe la menor duda de que esta profunda relación con el mundo judicial del siglo xVIII explica muchas de las posiciones esgrimidas por Mon-

39 "La Constitution délègue exclusivement au Corps législatif les pouvoirs et fonctions ci-après: $1 .^{\circ}$. De proposer et décréter les lois".

40 "Le Pouvoir exécutif ne peut faire aucune loi, même provisoire, mais seulement des proclamations conformes aux lois, pour en ordonner ou en rappeler l'exécution.

41 Léon DUGUIT: Las transformaciones..., op. cit., p. 159.

42 Léon DUGUIT: La separación de poderes y la Asamblea Nacional de 1789, CEC, Madrid, 1996, en especial, pp. 28-34.

43 Georges VEDEL: Droit Constitutionnel, op. cit., p. 71.

44 Recordemos que en el Capítulo I del Libro segundo de su obra Del espíritu de las leyes (manejamos la edición traducida por Mercedes Blázquez y Pedro de Vega y editada por Tecnos, $2 .^{a}$ ed., Madrid, 1993), Montesquieu diferencia tres clases de Gobierno: el republicano (aquel en el que el pueblo entero, o parte del pueblo, tiene el poder soberano), el despótico (en el que una sola persona sin ley y sin norma, lleva todo según su voluntad y su capricho), y el monárquico (aquel en el que gobierna uno solo, con arreglo a leyes fijas y establecidas). 
tesquieu en su celebérrima obra L'esprit des lois en relación a los jueces, particularísimamente en el Capítulo VI ("De la Constitución de Inglaterra") del Libro undécimo ("De las leyes que dan origen a la libertad política en su relación con la Constitución" $)^{45}$.

El punto de partida de la doctrina de Montesquieu es universalmente conocido: "Es una experiencia eterna — dirá Charles-Louis de Secondat ${ }^{46}$ — que todo hombre que tiene poder siente la inclinación de abusar de él, yendo hasta donde encuentra límites". De ahí que sea necesario limitar al poder, para lo que Montesquieu atisba como remedio que el poder frene al poder ${ }^{47}$. Con ello, el ilustre pensador estaba condenando sin paliativos el gobierno por él mismo tildado de despótico. La solución del problema la encuentra Montesquieu en la separación de los tres poderes que existen en cada Estado ${ }^{48}$. El bordelés considera que no habría libertad si el poder judicial no estuviera separado del legislativo ni del ejecutivo. Influido, desde luego, por el pensamiento de otros autores, especialmente por John Locke, que ya en su Essay on civil government había diferenciado tres poderes, el barón de la Brède contribuye de modo decisivo a consagrar el principio que, como dijera Esmein ${ }^{49}$, estaba destinado a llegar a ser uno de los artículos del "Credo" elaborado por los filósofos franceses del siglo XVIII. Toda la argumentación de Montesquieu girará en torno a la necesidad de salvaguardar la libertad a través de la separación de poderes, que a su vez garantizaba el que cada poder se ejerciera legalmente y, por lo mismo, sin abusos.

Ahora bien, por lo que nos interesa en este trabajo, hemos de plantearnos la importante cuestión del rol del poder judicial. De lo ya señalado pareciera derivarse con gran nitidez que el poder judicial era concebido por Montesquieu como un poder perfectamente delimitado de los otros dos. Ello, sin embargo, no puede ser admitido sin notables matices, como, entre otros, pusieran de re-

45 Es ésta una tesis comúnmente admitida por la doctrina, como ejemplifican las posiciones de Maurice HAURIOU (en Principios de Derecho público..., op. cit., p. 336) y de Mauro CAPPELLETTI (en "Montesquieu abandonné? Développement et legitimité de la "justice constitutionnelle", artículo recogido en su obra Le pouvoir des juges, Economica/Presses Universitaires d'Aix-Marseille, París, 1990, pp. 249 y ss.; en concreto, pp. 258-259), aunque ambos autores discrepen en torno a si Montesquieu partía de la idea de que el juez tenía un poder político, tesis que hará suya Hauriou —quien la ve corroborada en el poder d'empêcher, es decir, de contener a los otros poderes, que Montesquieu atribuye a los jueces_-, o si, por el contrario, como sostiene Cappelletti, Montesquieu defendió la tesis de que ningún poder de naturaleza política debía reconocerse a los jueces, tesis ésta con la que nos sentimos identificados.

46 Capítulo VI del Libro undécimo.

47 "Para que no se pueda abusar del poder es preciso que, por la disposición de las cosas, el poder frene al poder". Capítulo IV del Libro undécimo.

48 “Todo estaría perdido — afirmará Montesquieu (Capítulo VI del Libro undécimo) — si el mismo hombre, el mismo cuerpo de personas principales, de los nobles o del pueblo, ejerciera los tres poderes: el de hacer las leyes, el de ejecutar las resoluciones públicas y el de juzgar los delitos o las diferencias entre particulares".

49 A. ESMEIN: Éléments de Droit Constitutionnel français et comparé, septième édition revue par Henry Nézard, tome premier, Recueil Sirey, Paris, 1921, p. 464. 
lieve Carré de Malberg ${ }^{50}$ y Duguit ${ }^{51}$. Recordemos al efecto que en el propio Capítulo sobre "la Constitución de Inglaterra", Montesquieu comienza aplicando al poder judicial la denominación de "poder ejecutivo de los asuntos que dependen del Derecho civil", frente al poder ejecutivo propiamente dicho, que es conceptuado como «el poder ejecutivo de los asuntos que dependen del Derecho de gentes". Y aunque más adelante diferencia estos dos poderes, atribuyendo al que ahora llama "poder judicial" la potestad de castigar los delitos o juzgar las diferencias entre particulares, subsiste de la primera denominación común de potestad ejecutiva, aplicada por igual a ambas funciones, la idea de que deben juntarse en un concepto común de ejecución. En otro lugar ${ }^{52}$, de L'Esprit des lois, Montesquieu precisará su doctrina al señalar: «En el Gobierno republicano es propio de la naturaleza de la constitución que los jueces sigan la letra de la ley». Y en el varias veces mencionado Capítulo VI del Libro undécimo, perfilará aún más esta idea al significar: «Pero si los tribunales no deben ser fijos, sí deben serlo las sentencias, hasta el punto que deben corresponder siempre al texto expreso de la ley. Si fueran una opinión particular del juez, se viviría en la sociedad sin saber con exactitud los compromisos contraídos con ella". "Podría ocurrir —admite el bordelés en el mismo Capítulo- que la ley, que es ciega y clarividente a la vez, fuera, en ciertos casos, demasiado rigurosa". Sin embargo, ni tan siquiera en tales supuestos se admite una intervención mitigadora de tal rigor por parte de los jueces: «Les juges de la nation ne sont, comme nous avons dit, que la bouche qui prononce les paroles de la loi; des êtres inanimés qui n'en peuvent modérer ni la force ni la rigueur". Es por ello por lo que de los tres poderes a que se refiere Montesquieu, «el de juzgar es, en cierto modo, nulo". Estas reflexiones parecen dejar claramente puesto de relieve que, a diferencia de Locke, Montesquieu no considera la autoridad judicial como uno de los tres poderes del Estado.

Esta concepción, por la que bien podría decirse que el poder judicial es «nulificado" como tal "poder", se convertirá en una idea central en el pensamiento francés. La Revolución proclamará como uno de sus principios medulares el de supremacía absoluta de la ley escrita establecida por el corps législatifintegrado por los representantes del pueblo, reduciendo la función de los tribunales, como dice Cappelletti $i^{53}$, al cumplimiento de una tarea que se visualiza como meramente mecánica: la aplicación de la ley a los casos concretos. Ciertamente, ante esta situación, podríamos cuestionarnos el por qué del diseño del orden judicial como un poder independiente y autónomo por parte de los hombres de 1789-91. La razón la dio Duguit con toda evidencia ${ }^{54}$. La Asamblea Nacional

50 R. CARRÉ DE MALBERG: Teoría General del Estado, op. cit., pp. 653 y ss.

51 Léon DUGUIT: La separación de poderes y la Asamblea Nacional de 1789, op. cit., p. 82.

52 Capítulo III del Libro sexto.

53 Mauro CAPPELLETTI: «Montesquieu abandonné? Developpement et légitimité de la "justice constitutionnelle", op. cit., p. 260

54 Léon DUGUIT: La separación de poderes y la Asamblea..., op. cit., pp. 82 y 21, particularmente. 
tomó prestada la idea de la Constitución norteamericana, en la que, sin embargo, la creación de un poder judicial, independiente de los otros y competente para juzgar la constitucionalidad de las leyes, encontraba una necesidad específica: resolver los posibles conflictos entre la Unión y los Estados, que sólo un poder completamente independiente podría dilucidar con soberana imparcialidad. También creyó encontrarla en la obra de Montesquieu, cuando, por el contrario, como ya se ha expuesto, en el pensamiento del bordelés el orden judicial no constituía en rigor un poder distinto y autónomo.

Desde una perspectiva orgánica, no dejan de ser asimismo significativas algunas de las reflexiones que en el mismo Capítulo relativo a la Constitución de Inglaterra hace Montesquieu, y que no pueden por menos, a nuestro juicio, que considerarse tributarias del conocimiento tan cercano que el insigne pensador tenía de la situación en su tiempo de las autoridades judiciales, en definitiva, del Parlement de Paris y de los Parlements provinciaux. Cree el barón de la Brède que "el poder judicial no debe darse a un Senado permanente, sino que lo deben ejercer personas del pueblo, nombradas en ciertas épocas del año de la manera prescrita por la ley, para formar un tribunal que sólo dure el tiempo que la necesidad lo requiera". De esta manera, concluye Montesquieu, "el poder de juzgar, tan terrible para los hombres, se hace invisible y nulo, al no estar ligado a determinado estado o profesión.

Los revolucionarios seguirán estas ideas muy de cerca. El artículo $5 .{ }^{\circ}$ del Preámbulo del Título III de la Constitución de 1791 prescribirá al efecto: «Le Pouvoir judiciaire est délégué à des juges élus à temps par le peuplen. Y el artículo 2. ${ }^{\circ}$ del Capítulo V del mismo Título dispondrá: "La justice sera rendue gratuitement par des juges élus à temps par le peuple.... ${ }^{55}$. Estas previsiones podrían inducir a pensar que los fundadores del nuevo Derecho público francés consideraron la función jurisdiccional como una actividad esencialmente diferente de aquélla que calificaban como ejecutiva. Sin embargo, no fue así, pues, como antes se dijo, si por un lado el orden judicial pareció constituir un poder autónomo e independiente, por otro, la ordenación normativa de los revolucionarios demostró que ello no era así. Para Carré de Malberg ${ }^{56}$, no se puede dudar de que la Constitución de 1791, aunque en apariencia y desde el punto de vista orgánico asigne la dignidad de tercer poder a la justicia, se haya atenido, en el fondo y desde el punto de vista funcional, al concepto de los dos poderes.

El carácter electivo de los jueces, como quedó claro en el debate que tuvo lugar en el mes de mayo de 1790, se justificó con una lógica cartesiana. Si todos los poderes eran manifestaciones inmediatas de la soberanía nacional ${ }^{57}$, debían

$55 \mathrm{Al}$ carácter electivo de los jueces habría de añadirse el principio de inamovilidad de los mismos. El propio artículo $2{ }^{\circ}$ del Capítulo V prescribía: «Ils (les juges) ne pourront être, ni destitués que pour forfaiture dûment jugée, ni suspendus que pour une accusation admise".

56 R. CARRÉ DE MALBERG: Teoría general..., op. cit., pp. 653-654.

57 Así vendrían a recogerlo, por lo demás, los artículos $10^{\circ}$ y $2{ }^{\circ}$ del Preámbulo del Título III de la Constitución de 1791. Mientras la primera de esas normas señalaba que: «La Souveraineté est une, 
ser conferidos directamente por la propia Nación; siendo el poder judicial uno de tales poderes, quienes lo ejercen, esto es, los jueces, debían ser elegidos por la Nación. Esta lógica no había de conducir hasta sus últimas consecuencias: la conformación del Judiciary como un auténtico "poder " ${ }^{58}$. En similar dirección, Esmein señalarás9 que "l'élection des juges n'est point imposée par la thèse qui voit dans l'autorité judiciaire un troisième pouvoir", para añadir que lo que muestra más bien es que el carácter electivo de los jueces puede existir allí donde se sostiene y declara que la autoridad judicial entra en el ámbito del poder ejecutivo, si bien, en otro momento ${ }^{60}$, Esmein parece decantarse por la tesis de que la administración de justicia constituye natural y racionalmente una manifestación especial de la soberanía, un poder distinto. En cualquier caso, por nuestra parte, concordamos, como ya hemos tenido oportunidad de señalar, con Carré de Malberg en su apreciación de que, pese a las muchas contradicciones ya expuestas, en la época revolucionaria la jurisdicción se consideró como una función de pura aplicación, y por lo tanto también de ejecución de las leyes.

De esta forma, el principio de separación de poderes se concebirá de modo radicalmente diferente a como se había visualizado por los constituyentes de Filadelfia, pese al influjo que la Constitución norteamericana ejerció sobre los revolucionarios franceses, y ello no sólo por la notable rigidez con que tal principio se establece, en franco contraste con el equilibrio que con él se trata de alcanzar en Norteamérica (checks and balances), concepción que no sin algún matiz ha llegado a nuestros días ${ }^{61}$, sino también porque, en el marco de esa división, el poder judicial, en perfecta sintonía con el pensamiento de Montesquieu, quedará relegado a un rol secundario, bien diferente del que habría de asumir en los Estados Unidos. Innecesario es decir que de la divergencia apuntada se deriva un lastre insuperable para que los jueces pudieran llevar a cabo una función de judicial review análoga a la que asumiría el Judiciary norteamericano.

\section{EL MITO DEL «GOBIERNO DE LOS JUECES"}

Un nuevo argumento se unirá a los anteriores bien que el mismo no sea fruto del pensamiento revolucionario sino de una obra de un enorme impacto pu-

indivisible, inaliénable et imprescriptible. Elle appartient à la Nation", la segunda comenzaba así: "La Nation, de qui seule émanent tous les Pouvoirs.....

58 Ello no obstante, Duguit recuerda que con ocasión de la aprobación del artículo 5. ${ }^{\circ}$ del Preámbulo del Título III, pareció quedar claro que el pensamiento de todos los que lo votaron se inclinaba por una percepción del poder judicial como un "poder distinto y autónomo". Léon DUGUIT: La separación de poderes..., op. cit., p. 88.

59 A. ESMEIN: Éléments de Droit Constitutionnel français et comparé, op. cit., p. 506.

60 Ibidem, p. 502.

61 Davis, refiriéndose a la concepción francesa acerca del principio de la separación de poderes y a su radical diferenciación de la visión norteamericana del mismo principio, señala: «Perhaps 
blicada en 1921 que vendrá a crear una suerte de mito resistente tanto al devenir del tiempo como al cambio de las circunstancias. Nos referimos obviamente a la obra de Edouard Lambert sobre le gouvernement des juges ${ }^{62}$. Para dar una idea de la relevancia del concepto acuñado por Lambert, bastará con señalar que, a juicio de Favoreu, que sigue el criterio del norteamericano Davis, "ce concept joue en France à peu près le même rôle symbolique et flou que celui de "rule of law" aux États-Unis" ${ }^{63}$. El propio Davis, Profesor de Cleveland y excelente conocedor de la cultura jurídica francesa, señala ${ }^{64}$ que la expresión government of judges pronto entró en el lenguaje del Derecho público francés e incluso en el de la cultura popular, derivando gran parte de su fuerza, sin duda alguna, de la histórica aversión francesa a un strong judiciary, y llegando a ser una auténtica catch-phrase.

El impacto de la obra de Lambert fue casi inmediato, como ocho años después de publicada constataba Duez: "l'ouvrage récent du professeur Lambert (...) a eu un retentissement aussi éclatant que justifié, chez les publicistes français" " ${ }^{65}$. La mitología del "gobierno de los jueces" no se circunscribirá a Francia; bien al contrario, la expresión sería plenamente recepcionada por la literatura jurídica europea para designar una serie de situaciones patológicas en las relaciones entre el poder judicial y los restantes poderes del Estado, muy en particular, el poder legislativo. D'Orazio lo ha puesto de relieve con singular claridad en su "Presentación" de la relativamente reciente versión italiana de la obra de Lambert: "Quel titolo, appunto (Government by Judiciary) ha assunto, nella letteratura europea, il significato emblematico per indicare un complesso di situazioni patologiche nei rapporti tra organi giudiziari ed organi di indirizzo politico, con evidente alterazione nell'equilibrio istituzionale complessivo: in sintesi, lo sconfinamento dei giudizi dai limiti della loro funzione e l'invasione (di varia gravità, forma e misura) della sfera di discrezionalità e di responsabilità

the most concise description of the "functional" doctrine is that of a "mutual independence of the principal organs", as opposed to the American system of checks and balances. This doctrine is far more "rigid", perhaps absolutely so, that its more "flexible" American conterpart". Michael H. DAVIS: "The Law/Politics Distinction, the French Conseil Constitutionnel, and the U. S. Supreme Court", en The American Journal of Comparative Law, vol. 34, núm. 1, winter 1986, pp. 45 y ss.; en concreto, p. 48.

62 Edouard LAMBERT: Le gouvernement des juges et la lutte contre la législation sociale aux États-Unis (L' expérience américaine du contrôle judiciaire de la constitutionnalité des lois), Marcel Giard, Paris, 1921. Manejamos para este trabajo la versión italiana de la citada obra, Il governo dei giudici e la lotta contro la legislazione sociale negli Stati Uniti (L' esperienza americana del controllo giudiziario della costituzionalità delle leggi), Giuffrè, Milano, 1996.

63 Louis FAVOREU: "Le Conseil Constitutionnel et la cohabitation", separata del trabajo presentado por el Prof. Favoreu a las Jornadas de Estudios organizadas por la "Association Française de Science Politique" los días 3 y 4 de abril de 1987 en París sobre el tema Un an de cohabitation à la française, p. 22.

64 Michael H. DAVIS: "A government of judges: an historical re-view", en The American Journal of Comparative Law, vol. 35, núm. 3, summer 1987, pp. 559 y ss.; en concreto, p. 559.

65 Paul DUEZ: "Le contrôle juridictionnel de la constitutionnalité des lois en France", en $M e ́-$ langes Maurice Hauriou, op. cit., p. 216. 
del legislatore e, quindi, una violazione dei principi della certezza del diritto e della separazione dei poteri, ${ }^{66}$.

Sin ánimo de entrar en este momento en la obra de Lambert, lo que haremos en un momento posterior, sí nos referiremos ahora a dos de sus críticas más duras en relación al modelo americano de la judicial review. De un lado, a juicio del Profesor de Lyon, el ejemplo americano nos muestra que el control judicial de la constitucionalidad de las leyes bien pronto dejó de ser un simple engranaje de la organización federal, para convertirse en un instrumento de vigilancia del poder judicial sobre el legislativo y sobre el ejecutivo, transformando así de modo radical la misma naturaleza de la Constitución que lo acogió ${ }^{67}$. De otro lado, y desde la perspectiva del contenido material de la jurisprudencia de la Supreme Court, se subraya por Lambert ${ }^{68}$ que la judicial review había desempeñado un rol criticable, y criticado, de freno frente a la legislación social.

En un estudio publicado años después, Lambert, tras analizar la jurisprudencia de la Supreme Court entre 1923 y 1927, insistiría en sus tesis, señalando ${ }^{69}$ que las decisiones judiciales norteamericanas conducían a un sistema tildado por el Justice George Sutherland (Justice entre 1922 y 1938), bien que antes de su incorporación a la Supreme Court, siendo senador, como une démocratie tempérée. Tales decisiones habían propiciado, a juicio del Profesor de Lyon, une constitution judiciaire économique que, bajo la cobertura de las Enmiendas V y XIV, se había superpuesto a la Constitución elaborada por la Convención de Filadelfia, abriendo un camino "aux constitutions politico-économiques, d'humeur opposée, que sont la constitution demi-révolutionnaire de Weimar et les constitutions franchement révolutionnaires de la Russie et de l'URSS".

Proyectando los efectos que Lambert encuentra en el modelo estadounidense hacia Francia, el Profesor que fundara en 1921, en el seno de la Universidad de Lyon, el Institut de Droit Comparé, el más antiguo tras el fundado cinco años antes por Rabel en Munich, pone de relieve ${ }^{70}$ que la introducción en Francia del veto giudiziario en una Constitución como la francesa, que ha dejado gran libertad al desarrollo de la legislación social, en un momento de plena maduración de tal legislación, aparecería a los ojos de las clases trabajadoras, especialmente de sus organizaciones de clase, esto es, de los sindicatos, como un intolerable gesto de desconfianza, con el subsiguiente riesgo de provocar reacciones que quizá no fueran tan pacíficas como la agitación norteamericana en favor del recall frente a los jueces del Tribunal Supremo, hecho que adquiriría su máxima expresión a raíz del conflicto que enfrentó a la Supreme Court y al Presidente Roosevelt con ocasión del New Deal.

66 Giustino D'ORAZIO, en la "Presentazione" a la obra de Edouard LAMBERT, Il governo dei giudici..., op. cit., pp. V-VI.

67 Edouard LAMBERT: Il governo dei giudici..., op. cit., p. 204

68 Ibidem, p. 206.

69 Edouard LAMBERT: "Quatre années d'exercise du contrôle de la constitutionnalité des lois par la Cour suprême des États-Unis", en Mélanges Maurice Hauriou, op. cit., pp. 467 y ss.; en concreto, pp. 502-503.

70 Edouard LAMBERT: Il governo dei giudici..., op. cit., pp. 206-207. 
La tesis de Lambert, como ya se ha dicho, impactó fuertemente, lo que no impidió que voces autorizadas se manifestaran en contra. Tal sería el caso de Duguit, a cuyo juicio ${ }^{71}$, con independencia ya de las tendencias políticas que puedan aparecer en la jurisprudencia del Tribunal Supremo norteamericano, en el poder reconocido a los tribunales estadounidenses de apreciar la constitucionalidad de las leyes, hay una institución notablemente protectora de la libertad individual frente al arbitrio del legislador. Y en relación específica al juicio crítico del que venimos ocupándonos, Duguit rechazaría que fuera exacto: "On ne peut pas dire qu'en Amérique les cours de justice, même la cour suprême, soient véritablement associées au governement; on ne peut même pas dire qu'elles exercent un véritable contrôle sur le Congrès". Por las mismas fechas que Duguit, en Italia, Einaudi se manifestaba acerca de la "erronea credenza" de Lambert ${ }^{72}$.

La noción del "gobierno de los jueces", siempre notablemente hostil frente al control judicial de constitucionalidad de las leyes, encierra en último término una común carga crítica: la falta de legitimidad democrática de los órganos jurisdiccionales, cuyos miembros no sólo no han sido elegidos sino que son irresponsables. La objeción es compendiada por Cappelletti en pocas palabras: "that judicial law-making is unacceptable because undemocratic" ${ }^{73}$. Ciertamente, no estamos ante una argumentación crítica circunscrita al caso francés; por el contrario, la misma objeción es reiterada en otros países, también incluso en los Estados Unidos ${ }^{74-75}$.

71 Léon DUGUIT: Traité de Droit Constitutionnel, tome troisième, 3ème édition, E. de Boccard, Paris, 1930, pp. 729-730.

72 M. EINAUDI: Le origini dottrinali e storiche del controllo giudiziario sulla costituzionalità delle leggi negli Stati Uniti d'America", Torino, 1931, pp. 15-16. Cit. por Giustino D'ORAZIO en la "Presentazione" de la obra de LAMBERT, Il governo..., op. cit., p. XVI.

73 Mauro CAPPELLETTI: "The Law-Making Power of the Judges and its Limits", en la obra del propio autor, The Judicial Power in Comparative Perspective (edited with the collaboration of Paul J. Kollmer and Joanne M. Olson), Clarendon Press, Oxford, 1989, pp. 3 y ss.; en concreto, p. 40.

74 Cfr. al efecto, Burton CAINE: "Judicial Review-Democracy versus Constitutionality", en Temple Law Quarterly (Temple University School of Law, Philadelphia, Pa), vol. fifty-six, 1983, pp. 297 y ss. Recuerda Caine que: "the major criticism of noninterpretativist judicial review has been the aseveration that it is undemocratic, leaving major policy decisions in the hands of an unelected and unaccountable judiciary. In a word, say the critics, such judicial decision-making is "undemocratic" in violation of basic assumptions of our government" (p. 318).

75 No es éste el momento de entrar a cuestionar lo infundado de la crítica de la falta de legitimidad democrática de la justicia constitucional; ello no obstante, no queremos dejar de señalar que la noción de democracia no puede ser reducida a una simple idea mayoritaria. Como dice Cappelletti, "democracy also means participation; and it means tolerance and freedom". Es por lo mismo por lo que "a judiciary reasonably independent from majoritariam whims can contribute much to democracy". Mauro CAPPELLETTI: "The Law-Making Power of the Judges...", op. cit., p. 46. Y en una dirección todavía más rotunda, Caine señala: "Experience has shown that the ultimate responsibility for checking the will of the people when it comes to issues of intense popular interest fallen mainly upon the judiciary, and that elected lawmakers and executives have been part of the problem, rather than part of the solution". Burton CAINE: "Judicial Review-Democracy versus Constitutionality", op. cit., p. 323. 
La peculiaridad del caso francés viene dada por la fuerza expansiva del concepto, por su persistencia histórica y por la virtualidad que el mismo ha tenido en orden a paralizar todo intento de establecer el control judicial de la constitucionalidad de las leyes, y una vez recepcionado dicho control, con la Constitución de 1958 y el impulso que al mismo diera el Conseil constitutionnel tras su celebérrima Decisión de 16 de julio de $1971^{76}$, como asimismo de resultas de la reforma constitucional de 1974, por su capacidad deslegitimadora de la importantísima función llevada a cabo por el Conseil constitutionnel como garante de los derechos y libertades frente al poder legislativo.

Sin ánimo alguno de exhaustividad, sí queremos, sin embargo, hacernos eco de algunas manifestaciones que corroboran o ejemplifican cumplidamente la persistencia en Francia del mito del gouvernement des juges. Autor tan relevante como Vedel, hace cuarenta años, se refería a cómo Francia era un país en el que «les gouvernants de tous bords sont vite prêts à crier au governement des juges ${ }^{77}$. En la misma dirección, Pisier, mucho más recientemente ${ }^{78}$, tras significar que en Francia, tras una larga ausencia, el control de la constitucionalidad se afirma como un hecho anclado en el corazón de las instituciones, matizaba que ello no obstante, "certains n'hésitent pas à faire de ce "triomphe de l'État de droit" une véritable "ménace pour la démocratie". La paradoja, heredera de una tradición profundamente gala, vuelve periódicamente "aux lèvres politiques les plus compulsives et n'en finit pas de ronger le coeur même de nos institutions".

A principios del pasado siglo, incluso entre autores decididamente partidarios de la implementación de la judicial review de tipo norteamericano, el temor al "gobierno de los jueces" no dejaba de suscitar recelos. Tal sería el caso de Hauriou, que, siendo favorable a la institución, rechazaba todo atisbo de poder político en manos del juez, para precisar de inmediato que el gran defecto del sistema americano era que, tal y como se encontraba organizado, hacía del juez un poder político y sometía a los Estados Unidos al "gobierno de los jueces" ${ }^{79}$. Tampoco Duguit escapa a la inquietud que le provoca tan "terrible mito": "La logique duguiste de l'État de droit s'accompagne bien de l'horreur du "gouvernement des juges" dont les actes doivent rester hiérarchiquement et étroitement subordonnés à un droit objectif, et donc à la loi, qui plus que n'importe quelle autre manifestation de droit positif, lui est présumée conforme " ${ }^{80}$. Otros autores, como Jèze, que admiten que ninguna objeción puede oponerse desde una

76 Cfr. al efecto, Louis FAVOREU y Loïc PHILIP: Les grandes décisions du Conseil constitutionnel, Sirey, 2. ${ }^{\text {a }}$ ed., París, 1979, pp. 235 y ss.

77 Georges VEDEL, en el "Préface" a la obra de Francine BATAILLER, Le Conseil d'État juge constitutionnel, LGDJ, París, 1966, p. V.

78 Evelyne PISIER: "Léon Duguit et le contrôle de la constitutionnalité des lois", en Droit, institutions et systèmes politiques. Mélanges en hommage à Maurice Duverger, Presses Universitaires de France, París, 1987, pp. 189 y ss.; en concreto, p. 190

79 Maurice HAURIOU: Principios de Derecho público y constitucional, op. cit., pp. 336-337.

80 Evelyne PISIER: “Léon Duguit et le contrôle de la constitutionnalité des lois", op. cit., p. 197. 
óptica jurídica al control jurisdiccional de las leyes, advierten por el contrario que lúgubres peligros se ciernen políticamente sobre tal control ${ }^{81}$.

El que a nuestro juicio bien podría tildarse de "efecto-parálisis" de este concepto se ha dejado sentir en muchos momentos clave - en lo que al control de la constitucionalidad de las leyes se refiere- de la Quinta República. No sólo la doctrina francesa lo ha constatado, como ya se ha puesto de relieve; también lo ha apreciado la doctrina especializada norteamericana e inglesa, que ha venido, por lo general, prestando bastante atención al caso francés. Y así, existe un cierto consenso en la apreciación de que en los debates preparatorios del texto de la Constitución de 1958 llevados a cabo en el seno del Comité Consultivo Constitucional la necesidad de evitar el "fantasma" del "gobierno de los jueces" estuvo omnipresente ${ }^{82}$. Más aún, la propuesta que prosperó en el seno del Comité en torno a la concesión de la saisine, esto es, de la legitimación para recurrir al Conseil, a un tercio de los miembros de cada Cámara, fue desestimada por el Gobierno de turno en base a que tal legitimación entrañaba el serio peligro de reviviscencia del "gobierno de los jueces" ${ }^{83}$. La trascendental Decisión del Conseil sobre la libertad de asociación, de 16 de julio de 1971, no quedaría inmune a la crítica recurrente de que, con ella, el Conseil había abusado de su poder e incurrido en una actuación propia del "government by judges" ${ }^{84}$.

Para terminar con esta cuestión diremos que aunque pudiera pensarse que la misma, hoy, con la extraordinaria creatividad jurisprudencial que ha llevado

81 "Le système de contrôle, par les juges, de la constitutionnalité intrinsèque de la loi serait, en France, très dangereux si l'on adoptait la théorie développée par certains auteurs modernes sur le caractère constitutionnel d'un grand nombre de principes généraux, plus ou moins vagues". Gaston JÈZE: "Le contrôle juridictionnel des lois", op. cit., p. 421. Tras advertir acerca del peligro que el control entraña, Jèze, para quien —no se olvide— jurídicamente ningún impedimento podía oponerse al control jurisdiccional de la ley (Ibidem, p. 403), significa que no estamos ante un peligro puramente hipotético, sino bien real: "Que l'on suppose, l'hypothèse n'est pas chimérique, des tribunaux ou même simplement une Cour suprême animés d'un esprit hostile aux réformes démocratiques, sociales ou fiscales. Sous prétexte de contrôle de la constitutionnalité intrinsèque des lois, ces tribunaux, cette Cour auraient le pouvoir redoutable et souverain de mettre en sommeil, pour des arguties juridiques, toutes les lois réalisant des réformes de ce genre. Ce serait le gouvernement des juges, ou plutôt le gouvernement d'une Cour suprême, d'un corps inamovible et irresponsable, suspect, par ses origines et la milieu social où il est recruté, de se poser en défenseur des privilèges des classes possédantes. On recommencerait l'histoire lamentable du Parlement de Paris de l'Ancien régime" (Ibidem, pp. 421-422).

82 "The discussions of the role of the Constitutional Council — dice Beardsley- are replete with references to the necessity of avoiding "government by judges". James E. BEARDSLEY: "The Constitutional Council and Constitutional Liberties in France", en The American Journal of Comparative Law, vol. XX, núm. 3, summer 1972, pp. 431 y ss.; en concreto, pp. 440-441.

83 "The committee which drew up the first draft of the constitution in 1958 had proposed that recourse should be open to one third of the members of either House, but the Government of the day, realising that this would greatly increase the political importance of the Conseil, and responding to the traditional fear of "government by judges" has adamantly opposed it". En tales términos se pronuncia Barry NICHOLAS, en "Fundamental Rights and Judicial Review in France" (part II), en Public Law, summer 1978, pp. 155 y ss.; en concreto, p. 155.

84 Cfr. al efecto, James E. BEARDSLEY: "The Constitutional Council and Constitutional Liberties in France", op. cit., p. 432. 
a cabo el Conseil constitutionnel, desarrollando una verdadera "revolución jurídica" en Francia, ha pasado a ser un mero recuerdo histórico, la realidad nos revela que ello no es así. En el subconsciente de la iuspublicística francesa, la idea, el temor, el rechazo al gouvernement des juges está lejos de desaparecer, por lo menos en bastantes sectores de la misma. Aportaremos como prueba de ello, a nuestro juicio bien significativa, alguna reflexión vertida en el debate celebrado entre los muy relevantes profesores franceses Jacques Robert y Dominique Rousseau, con ocasión del $40{ }^{\circ}$ aniversario de la V.. ${ }^{a}$ República ${ }^{85}$, en torno a los nueve años de experiencia como miembro del Conseil del primero de ellos. A la pregunta del Profesor Rousseau acerca de si el Conseil cumple bien su rol constitucional, el Profesor Robert, director de la Revue du Droit Public, efectúa, entre otras, las siguientes consideraciones: "Aujourd'hui le label de la démocratie c'est la Cour Constitutionnelle, mais il ne faut pas se dissimuler que si les cours constitutionnelles deviennent exigeantes et sévères, que restera-t-il de la loi? (...)". "La démocratie — se añade- est représentative; le pouvoir est donc aux élus. Il n'est pas aux juges qui d'ailleurs n'en veulent pas. Parler de "gouvernement des juges" est une erreur. Les juges ne veulent pas gouverner. Mais on les oblige parfois.... ${ }^{86}$. No creemos necesario por nuestra parte añadir nada más al respecto.

\section{EL RECHAZO DE TODA CAPACIDAD DE CREACIÓN DE DERECHO POR PARTE DEL JUEZ}

Una forma más elaborada de invocación al "gobierno de los jueces", como significara años atrás Favoreu ${ }^{87}$, es la que consiste en cuestionar las normas de referencia constitucional que viene utilizando el Conseil: la idea es que teniendo que aplicar disposiciones o principios de contenido incierto ${ }^{88}$ - se llegó a hablar de "principes introuvables, principes à géometrie variable, principes au contenu élastique ou aux effets aléatories-, el Conseil se otorga un poder de apreciación muy amplio, una enorme subjetividad en la interpretación y en la apreciación de la validez de las leyes. La enorme amplitud del bloc de constitutionnalité ha sido generalmente admitida, si bien, en los últimos años, ese proceso de progresiva ampliación de los parámetros de medición de la constitucionalidad de las leyes parece haberse moderado.

85 "Neuf années au Conseil constitutionnel" (Débat entre Jacques Robert et Dominique Rousseau), en Revue du Droit Public (numéro spécial sur "Les 40 ans de la Cinquième République), 1998, pp. 1748 y ss.

86 Ibidem, p. 1767

87 Louis FAVOREU: "Le Conseil Constitutionnel et la cohabitation", op. cit., pp. 25-26.

88 "Tout a été dit —afirma Loschak — sur la liberté que laissent au Conseil constitutionnel des dispositions ambiguës, vagues, parfois contradictoires, dont il détermine discrétionnairement la valeur juridique et les conditions d'application. De cette liberté dans le choix, l'interprétation et l'application des "principes à valeur constitutionnelle", on a frequemment souligné les conséquences politiques: le risque d'un gouvernement des juges". Danièle LOSCHAK: "Le Conseil constitutionnel protecteur des libertés", en Pouvoirs, núm. 13, 1980, pp. 33 y ss.; en concreto, p. 37. 
En cualquier caso, el cuestionamiento de este punto no es ni mucho menos nuevo, ni privativo del sistema de justicia constitucional configurado por la Constitución de 1958; nos bastará para constatarlo con recordar las reflexiones de Jèze, precedentemente expuestas, para ser conscientes de que se trata de un tema recurrente y reiterativo.

El problema de fondo, a nuestro modo de ver, no es tanto la mayor o menor vaguedad de los principios constitucionales que el Conseil extrae del bloque de la constitucionalidad sino más bien la cuestión de si el juez constitucional está capacitado o no para llevar a cabo una función creadora de Derecho. Drago, hace ya casi medio siglo, apuntaba como una de las razones impeditivas del control judicial de constitucionalidad en Francia la de que el Juez no crea Derecho como sucede en los países de common law, limitándose a ejercer una función de aseguramiento de la aplicación de las leyes ${ }^{89}$. Una vez más, hay que recurrir al pensamiento revolucionario para encontrar una explicación del histórico rechazo a la función creadora del Juez francés. Nos bastará por ahora con recordar el pensamiento ya expuesto de Montesquieu y con traer a colación la prohibición de las arrêts de règlement, llevada a cabo formalmente por el artículo 5 del Código Civil, que vedaría «aux juges de prononcer par voie de disposition générale et réglementaire sur les causes qui leur sont remises", estableciéndose con ello obviamente un impedimento real para la fijación de precedentes jurisprudenciales, lo que, como se verá más adelante, no sería sino una reacción dialéctica frente al uso y abuso que de este tipo de sentencias hicieron los Parlements del Ancien régime.

Ahora bien, ¿cabe pensar en rigor en una radical ausencia de creatividad - y por lo mismo, de vinculatoriedad general pro futuro- de las decisiones adoptadas con ocasión del control de constitucionalidad? El problema, ciertamente, presentaba muchísimo mayor interés históricamente, cuando, por ejemplo, durante la Tercera República, amplios sectores doctrinales reivindicaban atribuir al juez una función similar a la que realizan los Jueces norteamericanos a través de la judicial review. Las propias peculiaridades del sistema de control de constitucionalidad establecido en la Quinta República, en particular, el carácter previo del control y la imposibilidad, hoy por hoy, de que el mismo se suscite con ocasión de la aplicación de la ley en un caso concreto, al hilo de la exception d'inconstitutionnalité, instituto procesal objeto de un notable debate y que incluso se ha intentado introducir normativamente en dos ocasiones, aunque sin éxito ante el rechazo radical del Senado, restan interés a la cuestión, no obstante lo cual la misma todavía hoy sigue conservando actualidad. Piénsese que otros órganos jurisdiccionales son jueces constitucionales, aunque no lo sean de la ley, sino de las normas infralegales. Tal sería el caso del Conseil d'État ${ }^{90}$, pero tam-

89 Roland DRAGO: "General Comparative View of the French Constitution", en Obio State Law Journal (College of Law. The Ohio State University), vol. 21, 1960, pp. 535 y ss.; en concreto, p. 546.

90 "Le Conseil d'État — dirá Batailler- est un juge constitutionnel particulier, original, dans la mesure où il connaît des matières constitutionnelles, en dehors même de l'application de la règle 
bién, como subraya Fromont ${ }^{91}$, de todas las jurisdicciones judiciales y administrativas, que ejercen en Francia un control de constitucionalidad concreto sobre los actos de ejecución de las leyes, sean éstos judiciales o administrativos.

Por lo demás, al margen ya de las concretas particularidades del actual modelo francés de control de constitucionalidad, frente a la objeción histórica, aducida como un criterio impeditivo más del control judicial de constitucionalidad, de que el Juez francés no puede crear Derecho ni, por lo mismo, establecer precedentes jurisprudenciales, hemos de señalar, de un lado, que toda interpretación judicial es inevitablemente creativa, como dijera Cappelletti ${ }^{92}, \mathrm{y}$ de otro, y siguiendo un trabajo clásico de Fuller, que aun en ausencia de la doctrina del stare decisis, de vinculación jurisprudencial del precedente, toda decisión judicial incide de alguna manera y en cierto grado sobre relaciones jurídicas futuras ${ }^{93}$.

La problemática real no es, pues, la de establecer una contraposición entre una no creativa judicial interpretation y una judicial law-making, sino más bien la de determinar tanto el grado de creatividad (degree of creativity) como las formas, los límites y la aceptación del law-making through the courts ${ }^{4}$. Por lo demás, como ya en relación específica con el caso francés se ha señalado ${ }^{95}$, en cuanto el artículo $4 .^{\circ}$ del Código Civil prohibe al Juez, bajo pena de denegación de justicia, rehusar "de juger, sous prétexte du silence, de l'obscurité ou de l'insuffisance de la loin, tal disposición constituye un fundamento suficiente para reconocer el poder creador del Juez.

Al margen ya del Juez ordinario, cuyo rol, incluso creativo, es indudable que se vería enormemente potenciado de tener la facultad de plantear una

constitutionnelle au sens strict». Francine BATAILLER: Le Conseil d'État juge constitutionnel, op. cit., pp. 21 y ss.

91 Michel FROMONT: «Le contrôle de constitutionnalité excercé par les juridictions ordinaires françaises", en Der Verfassungsstaat vor neuen Herausforderungen (Festschrift für Ivo Hangartner), Dike Verlag, St. Gallen/Lachen, 1998, pp. 183 y ss.; en concreto, p. 183.

92 "Judicial "interpretation" — dirá Cappelletti— is unavoidably creative, even in the case "of apparently simple or direct language, in which legislative intent may have been expressed". Mauro CAPPELLETTI: "The Law-Making Power of the Judges...", op. cit., p. 5.

93 "Even in the absence of any formalized doctrine of stare decisis or res iudicata, an adjudicative determination will normally enter in some degree into the litigants'future relations and into the future relations of other parties who see themselves as possible litigants before the same tribunal. Even if there is no statement by the tribunal of the reason of its decision, some reason will be perceived or guessed at, and the parties will tend to govern their conduct accordingly" Lon L. FULLER: "The Forms and Limits of Adjudication", en Harvard Law Review, vol. 92, núm. 2, december 1978 , pp. 353 y ss.; en concreto, p. 357.

94 Como escribiera el Justice Oliver Wendell Holmes en 1899, wit is not true that in practice a given word or even a given collocation of words has one meaning and no other. A word generally has several meanings, even in the dictionary". Oliver W. HOLMES: "The Theory of Legal Interpretation", en Collected Legal Papers, 1952, p. 203. Cit. por Mauro CAPPELLETTI: "The Law-Making Power of the Judges...", op. cit., pp. 5-6

95 Jean Marie GARRIGOU-LAGRANGE: "Les partenaires du Conseil Constitutionnel ou de la fonction interpellatrice des juges", en Revue du Droit Public, 1986, núm. 3, pp. 647 y ss.; en concreto, p., 659 
cuestión de inconstitucionalidad ante el Conseil constitutionnel en torno a una norma que hubiese de aplicar en una litis de la que estuviere conociendo, es indiscutible, y así lo corrobora la realidad, que el Conseil constitutionnel ha desarrollado una labor notablemente creativa, muy en particular desde su célebre Decisión de 16 de julio de 1971, y aunque hay que entender que cuando el artículo 62 de la vigente Constitución, en el inciso final de su párrafo segundo, dispone que las decisiones del Conseil «'imposent aux pouvoirs publics et à toutes les autorités administratives et juridictionnelles", tal norma, de acuerdo con una jurisprudencia muy clásica de la Cour de cassation, vincula la autoridad de la cosa juzgada au dispositif, no extendiéndose aux motifs, salvo que tales motivos sean le soutien nécessaire du dispositif ${ }^{96}$, lo cierto es que tal doctrina, asumida por el Conseil desde sus primeros pronunciamientos ${ }^{97}$, ha propiciado que a través de la motivación de sus decisiones se cree una doctrina que, por lo general, ha sido seguida por los órganos jurisdiccionales y administrativos.

De cuanto se acaba de exponer se desprende, finalmente, la debilidad de esta forma de invocación al "gobierno de los jueces", para cuestionar la actuación del Conseil constitutionnel, aunque, históricamente, esa apelación al mito de tal gobierno judicial haya operado como un argumento adicional, a añadir a los ya expuestos precedentemente, en orden a imposibilitar en Francia todo tipo de control jurisdiccional de la constitucionalidad de las leyes.

\section{LA DIFUMINACIÓN DE LA DISTINCIÓN ENTRE EL PODER CONSTITUYENTE Y EL PODER LEGISLATIVO CONSTITUIDO}

Otro argumento que ha podido aducirse en orden a explicar el endémico rechazo del control judicial de constitucionalidad de la ley es el de la difuminación que en ciertos momentos históricos se ha producido en la distinción entre el poder constituyente y el poder legislativo constituido. Como diría Batai$1 l e r^{98}$, "la distinction entre pouvoir constituant et pouvoir législatif constitué s'estompe au profit de la toute puissance du Parlement, afirmación que tendría especial predicamento durante la Tercera República.

La Constitución norteamericana, como es bien sabido, a partir de una nítida separación entre el poder constituyente y los poderes que la misma constituía, consagraría la idea fundamental de que el pueblo era la fuente de todo poder, esto es, como diría Carré de Malberg99, el titular originario de todas las potesta-

96 Cfr. al respecto, François LUCHAIRE: Le Conseil Constitutionnel, op. cit., pp. 46-52.

97 En su Decisión 62-18 L, de 16 de enero, el Conseil constitutionnel razonará así: "que l'autorité des décisions visées par cette disposition (l'article 62 in fine de la Constitution) s'attache non seulement à leur dispositif mais aussi aux motifs qui en sont le soutien nécessaire et en constituent le fondement même.. Puede verse esta Decisión en Louis FAVOREU y Loïc PHILIP: Les grandes décisions du Conseil Constitutionnel, 2è édition, Sirey, Paris, 1979, pp. 161 y ss.

98 Francine BATAILLER: Le Conseil d'État juge..., op. cit., p. 17.

99 R. CARRÉ DE MALBERG: Teoría General del Estado, op. cit., p. 787. 
des que ejercen los diversos órganos estatales, por cuanto éstos, en efecto, derivaban su potestad respectiva de la delegación que de la misma les había hecho el pueblo por intermedio de la Constitución. No otra cosa se desprendería del Preámbulo de la Constitución de 1787: "We the People of the United States in order to form a more perfect Union... do ordain and establish this Constitution for the United States of America". Idéntica idea subyace, entre otras normas constitucionales, en la enmienda $\mathrm{X}^{100}$, que opone a los poderes delegados aquellos que, no estando comprendidos en la delegación, se encuentran por lo mismo en poder del pueblo, constituyendo, en este sentido, "poderes reservados".

Esta teoría pasó a Francia, introduciéndola Sieyès, que se sirvió de ella para atenuar lo que había de absoluto en el sistema de separación de poderes establecido por la Constitución de 1791. Recordemos que el inciso inicial del artículo 1. ${ }^{\circ}$ del Preámbulo del Título III de la Constitución declaraba: "La souveraineté est une, indivisible, inaliénable et imprescriptible». Sin embargo, tal norma debía conciliarse con el celebérrimo artículo 16 de la Declaración de Derechos de 1789, a cuyo tenor: "Toute societé dans laquelle la garantie des droits n'est pas assurée, ni la séparations des pouvoirs déterminée, n'a point de constitution". Como señalara Duguit ${ }^{101}$, la contradicción entre los dos principios era absoluta y el conflicto entre los mismos aparecería claramente cuando se discutió la organización del poder legislativo y la cuestión bicameral.

En la teoría de Rousseau no cabía concebir un poder constituyente superior al poder legislativo, con capacidad de obligar al mismo, puesto que, como ya se vio, el legislador no era sino el pueblo y, por lo mismo, el único soberano. A su vez, aunque la idea de un poder constituyente superior, fuente de los poderes constituidos, parece extraña al pensamiento de Montesquieu, lo cierto es que, como una vez más advirtiera Carré de Malberg ${ }^{102}$, la teoría de los tres poderes y de su reparto entre tres clases de órganos implicaba, en el fondo, y había de hacerla surgir necesariamente después, la teoría especial del poder constituyente, pues para explicar semejante reparto era evidentemente necesario llegar a la idea de una autoridad primitiva y superior que habría de situarse por encima de los titulares de los tres poderes, distribuyendo entre ellos sus respectivas competencias. Significativamente, en el Capítulo relativo a la Constitución de Inglaterra $^{103}$, se puede leer que: «el pueblo deberá realizar por medio de sus representantes lo que no puede hacer por sí mismo".

Sieyès construirá su doctrina sobre una base racional semejante a la de Montesquieu, a lo que unirá, también al igual que Montequieu, un elemento teleológico: la garantía y seguridad de los derechos. Como diría Bastid ${ }^{104}$, para Sieyès, toda unión social, y consiguientemente toda constitución política, no

100 "The powers not delegated to the United States by the Constitution, nor prohibited by it to the States, are reserved to the States respectively, or to the people".

101 Léon DUGUIT: La separación de poderes y la Asamblea...", op. cit., pp. 24-25, y en relación con el artículo 16 de la Declaración, pp 22-27.

102 R. CARRÉ DE MALBERG: Teoría General..., op. cit., pp. 1188-1189.

103 MONTESQUIEU: Del espíritu de las leyes, op. cit., Capítulo VI del Libro undécimo.

104 Paul BASTID: Sieyès et sa pensée, Hachette (nouvelle édition), Paris, 1970, p. 360. 
puede tener por objeto más que "de manifester, d'étendre et d'assurer les droits de l'homme et du citoyen". Por lo mismo, para el abate de Frejus, los representantes de la Nación francesa, al ejercer el poder constituyente, deben ante todo consagrarse a reconocer tales derechos. Esta idea inspirará buena parte de la obra de Sieyès y, entre otros aspectos, se manifestará de modo inequívoco en dos de los textos elaborados por el autor del "Ensayo sobre los privilegios": el "Préliminaire de la constitution; reconnaissance et exposition raisonnée des droits de l'homme et du citoyen", cuyo preámbulo va fechado el 22 de julio de 1789, y la "Déclaration des droits de l'homme en societé", que aparece transcrita en los Archives Parlementaires como anexo a la sesión del 12 de agosto, yendo seguida de un "Projet de constitution" apócrifo.

La doctrina de quien, pese a su condición de eclesiástico, se incorporó a los États Généraux representando al "Tiers état" del municipio de París, se vertebrará en torno a otra idea de la que se ocupa in extenso en su celebérrima obra Qu'est-ce que le Tiers état?: la Constitución, que obliga a las autoridades constituidas, cuyas potestades delimita, no puede obligar a la nación misma. "Non seulement — dirá Sieyès ${ }^{105}$ - la nation n'est pas soumise à une constitution, mais elle ne peut pas l'être, mais elle ne doit pas l'être, ce qui équivaut encore à dire qu'elle ne l'est pas". Con ello, como diría Carré de Malberg ${ }^{106}$, Sieyès no hacía sino trasladar a la nación, declarada soberana, la aplicación del principio, afirmado por Bodino y conservado en vigor hasta el fin de la monarquía del Antiguo Régimen, según el cual el príncipe, como soberano, se halla supra leges y queda legibus solutus ${ }^{107}$. En definitiva, la nación no puede jamás despojarse de su libertad de querer mediante su Constitución, sólo constituye y obliga a sus poderes constituidos, pero no a sí misma. En su "Exposición razonada" del 22 de julio de 1789, Sieyès señalaba: "Lo que se constituye no es la nación sino su establecimiento político... La Constitución de un pueblo sólo puede ser la Constitución de su Gobierno... Los poderes comprendidos en el establecimiento público se encuentran todos ellos sometidos a leyes, a reglas, a formas, que no son dueños de cambiar. Así como no pudieron constituirse a sí mismos, tampoco pueden cambiar su Constitución... El poder constituyente todo lo puede en este orden. No está sometido previamente a una Constitución dada. La nación, que entonces ejerce el más grande y el más importante de sus poderes, en esta función debe hallarse libre de toda coacción, de toda forma distinta de la que le place adoptar ${ }^{108}$.

105 Emmanuel SIEYÈS: Qu'est-ce que le Tiers état, (édition critique avec une introduction et notes par Roberto Zapperi), Librairie Droz, Genève, 1970, p. 182.

106 R. CARRÉ DE MALBERG: Teoría General..., op. cit., p. 1193

107 "Une nation — se afirma en otro pasaje del Capítulo V de la célebre obra de Sieyès— ne doit pas se mettre dans les entraves d'une forme positive. Ce serait s'exposer à perdre sa liberté sans retour, car il ne faudrait qu'un moment de succès à la tyrannie, pour dévouer les peuples, sous prétexte de constitution, à une forme telle, qu'il ne leur serait plus possible d'exprimer librement leur volonté et par conséquent de secouer les chaînes du despotisme. On doit concevoir les nations sur la terre comme des individus hors du lien social ou, comme l'on dit, dans l'état de nature".

108 Archives parlementaires, vol. VIII, p. 259. Cit. por R. CARRÉ DE MALBERG: Teoría General del Estado, op. cit., p. 1195. 
Encontramos en esta Exposición, claramente establecida, la distinción entre los poderes constituidos y el poder constituyente, que, como recuerda Esmein ${ }^{109}$, será presentada por Sieyès, en el Discurso en la Convención del 2 Thermidor del año III, como una de las primeras conquistas de la Revolución francesa, incluso como un producto del genio nacional, bien que no quepa olvidar que la idea sobre la que se asienta había encontrado sus primeras aplicaciones jurídicas en los Estados Unidos.

La diferenciación fue ya recepcionada por la Constitución de 1791 y, desde entonces, la mayoría de los textos constitucionales franceses la han seguido, estableciendo de modo expreso un procedimiento particularizado para su propia reforma. Tres Constituciones ignorarían, sin embargo, tal separación: la del 22 Frimario del año VIII (13 de diciembre de 1799) y las Cartas de 1814 y 1830. Las Leyes constitucionales de 1875 sí contemplarían dicha diferenciación; y así, en el artículo $8 .^{\circ}$ de la Ley constitucional de 25 de febrero de 1875 , se disponía: «Les Chambres auront le droit, par déliberations séparées prises dans chacune à la majorité absolue des voix, soit spontanément, soit sur la démande du Président de la République, de déclarer qu'il y a lieu de reviser les lois constitutionnelles. Après que chacune des deux Chambres aura pris cette résolution, elles se réuniront en Assemblée nationale pour procéder à la revision". Sin embargo, como después se verá, el hecho de que el Parlamento quedara investido de una absoluta libertad interpretativa respecto de la Constitución, relativizaría hasta el extremo la diferenciación entre el poder constituyente y el poder legislativo.

Por lo demás, si la tradición escrita francesa se ha orientado en el sentido de recepcionar la aludida diferenciación, la tradición histórica, como dice Bastid ${ }^{110}$, en gran parte, se ha hecho en sentido contrario, pues la revolución ha sido a menudo el medio empleado para provocar los cambios que deseaba la fracción más revoltosa de la opinión, y de ello ha resultado que hayan sido Asambleas Constituyentes soberanas, o que por tal se consideraban, las que elaboraran las nuevas leyes fundamentales.

En definitiva, la historia constitucional francesa nos revela una notable relativización de la distinción entre el poder constituyente y los poderes constituidos por cuanto la rigidez constitucional, una consecuencia de la supremacía de la Constitución y de la sujeción a la misma de todos los poderes por ella creados, particularmente del poder legislativo, no siempre se encuentra en los textos constitucionales franceses, y en ocasiones, aún encontrándose, no ha sido suficiente para posibilitar una clara diferenciación entre el poder constituyente y el poder legislativo, y de resultas, entre ley constitucional y ley ordinaria.

El problema presentaría una fisonomía particular entre 1814 y 1848, entre otras razones, por el hecho del absoluto silencio de las Cartas de 1814 y 1830, y también por la circunstancia de que, a diferencia de la Tercera República, el ti-

109 A. ESMEIN: Élements de Droit constitutionnel..., op. cit., tome premier, p. 573.

110 Paul BASTID: Sieyès et sa pensée, op. cit., p. 592 
tular del poder constituyente no era el pueblo ${ }^{111}$. Pero en 1875 , al margen ya de que no se discutiera que era el pueblo el titular último del poder constituyente, lo cierto es que, desde la óptica que ahora nos ocupa, nos ibamos a encontrar con una situación no muy distante respecto de la existente en la Restauración y en la Monarquía de julio. Como señalara Carré de Malberg ${ }^{112}$, existía una diferencia puramente nominal entre la norma constitucional y la norma legislativa, bien que el Profesor de Estrasburgo, no sin incurrir en una cierta contradicción, como se ha puesto de relieve ${ }^{113}$, atemperaría su inicial afirmación, que en pura lógica conducía a que fuera el Parlamento quien, libremente, decidiera si una ley debía ser constitucional u ordinaria, señalando que al Presidente de la República correspondía la facultad de no promulgar una ley manifiestamente inconstitucional. Ello no obstante, de la posición global de Carré de Malberg no se puede deducir que se adhiriera a la tesis sostenida por Laband de que la promulgación tiene valor de "juicio", es decir, de una apreciación relativa a la cuestión de saber si la ley ha sido creada, bien por cuanto al fondo, bien por cuanto a la forma, de conformidad con el orden constitucional. Esta tesis, sostenida como se acaba de decir por Laband, pero también por Jellinek, sería rechazada explícitamente por Carré de Malberg ${ }^{114}$, quien no la consideraría aceptable para el Derecho público francés ${ }^{115}$. En definitiva, sería el Parlamento quien tendría el monopolio, a lo largo de la III República, para interpretar la Constitución, lo que obviamente nos situaba ante una falta de diferenciación real entre las leyes constitucionales y las ordinarias.

A modo de resumen, puede afirmarse que aún aceptando que, como dice Duguit ${ }^{116}$, "la distinction des lois constitutionnelles rigides et des lois ordinaires a profondement pénétré tout notre droit public", lo cierto es que a lo largo de la historia constitucional francesa encontramos períodos en que tal diferenciación se ha visto relativizada si es que no, lisa y llanamente, ignorada. La diferenciación ha operado más como un principio teórico de separación entre el poder constituyente y los poderes constituidos que como un principio jurídicamente

111 Cfr. al efecto, Joseph BARTHÉLEMY: "La distinction des lois constitutionnelles et des lois ordinaires sous la Monarchie de juillet, en Revue du Droit Public, tome vingt-sixième, 1909, pp. 5 y ss.; en concreto, p. 7.

112 R. CARRÉ DE MALBERG: "La constitutionnalité des lois et la Constitution de 1875", en Revue Politique et Parlementaire, septembre 1928, p. 342.

113 Eric MAULIN: «Le principe du contrôle de la constitutionnalité des lois dans la pensée de R. Carré de Malberg", en Revue française de Droit constitutionnel, núm. 21, 1995, pp. 79 y ss.; en concreto, p. 91.

114 R. CARRÉ DE MALBERG: Teoría General..., op cit., pp. 415-416.

115 No sería este el caso de Waline, para quien la promulgación de las leyes por el Presidente de la República durante la III República tenía, entre otras funciones, una función jurisdiccional por mor de la cual, el Presidente, antes de promulgar la ley, tenía que examinar la regularidad del procedimiento seguido. De este carácter jurisdiccional de la intervención presidencial se derivaba la imposición a los tribunales del texto legal. Marcel WALINE: "Éléments d'une théorie de la juridiction constitutionnelle en Droit positif français", en Revue du Droit Public, tome quarante-cinquième, 1928, pp. 441 y ss.; en concreto, pp. $452-453$

116 Léon DUGUIT: Traité de Droit Constitutionnel, tome III, op. cit., p. 709. 
operativo del que hubiera de desprenderse la lógica consecuencia de una limitación y control del poder legislativo. Y ello, a nuestro entender, puede visualizarse como un nuevo argumento, de menor peso específico que los precedentes, aunque sólo sea por el reconocimiento en el plano teórico del principio de separación, en el que fundamentar el histórico rechazo del control judicial de la constitucionalidad de las leyes.

\section{LA DEVALUACIÓN Y FRAGILIDAD DE LAS CONSTITUCIONES}

Hemos de referirnos, finalmente, a un argumento adicional que bien puede ser aportado ad abundatiam a los fines que ahora interesan. Nos referimos a la devaluación y fragilidad de las Constituciones francesas.

a) La devaluación sería la resultante de que en algunos casos la Constitución ha sido un mero estatuto orgánico, o como dice Grosser ${ }^{117}$, "une simple mécanique permettant de faire fonctionner la vie institutionnelle". Ejemplo paradigmático de lo que acaba de decirse lo encontramos en las Leyes constitucionales de la Tercera República, que no enunciarían ningún principio de carácter material y que no eran sino un "mero catálogo de procedimientos y disposiciones concernientes al modo de designación de los poderes públicos y a las relaciones entre ellos" ${ }^{118}$. La exclusión constitucional, por lo menos desde la III República, de previsiones relativas a los derechos y a sus garantías, objeto de meras referencias en el ámbito del Preámbulo, de alcance más filosófico que jurídico, no dejaría de tener sus consecuencias en lo que al control judicial de constitucionalidad se refiere, relativizando el interés del control de constitucionalidad, por lo menos desde la perspectiva de los individuos, pues, por ejemplo, de existir en la Tercera República tal control, se habría debido a circunscribir a hacer respetar el orden de competencias constitucionalmente establecido, frente a lo que verdaderamente hubiera podido interesar a los ciudadanos: lograr el respeto de sus derechos.

Por otra parte, durante la primera mitad del siglo XIX, particularmente tras la Restauración, el pacto a que condujo el liberalismo doctrinario entre Parlamento y Monarca, se tradujo en la conversión de la ley en el instrumento de reproducción del pacto entre pueblo y Rey. La tensión ideológica desapareció, entrándose de esta forma en una especie de utopismo constitucional mágico, como lo denomina De Vega ${ }^{119}$, conforme al cual, porque la Constitución no es atacada, tampoco necesita ser defendida.

117 Alfred GROSSER: "Cours constitutionnelles et valeurs de référence" (A propos de décisions sur l'avortement), en Pouvoirs, núm. 13, 1980, pp. 117 y ss.; en concreto, p. 120

118 François GOGUEL: "El Consejo Constitucional francés", en la obra colectiva Tribunales Constitucionales Europeos y Derechos Fundamentales, CEC, Madrid, 1984, pp. 293 y ss.; en concreto, p. 294

119 Pedro DE VEGA, en el "Prólogo" a la versión española de la obra de Carl SCHMITT, Der Hüter der Verfassung, publicada con el título, La defensa de la Constitución (Estudio acerca de las 
b) La fragilidad de las Constituciones es en buena medida el fruto de su amplio número y, en muchos casos, de su fugaz vigencia. Tantas y tantas Constituciones se han sucedido entre 1791 y 1875 que, como diría Rivero ${ }^{120}$, la opinión se ha acostumbrado a no ver en ellas más que documentos precarios condenados a hundirse con los regímenes que las habían elaborado. De ahí a cuestionarse el por qué de la subordinación de la ley que permanece a la Constitución que pasa, media un paso. El contraste con los Estados Unidos es muy revelador a este respecto. Y así lo ha puesto de relieve la doctrina. Una de las diferencias que puede explicar el muy divergente rol del control de constitucionalidad de las leyes entre ambos países es que frente a la Constitución única norteamericana, en Francia se han sucedido quince Constituciones. "One may say — afirma Tallon ${ }^{121}$ — that changing the constitution is a national sport in France". Por lo demás, conviene no olvidar que mientras las Constituciones quebraban en su totalidad, las leyes ordinarias, como recordaba Esmein ${ }^{122}$, pese a las revoluciones, pese a los cambios operados en la forma de Estado, subsistían hasta tanto fueran implícita o explícitamente abrogadas por leyes nuevas ${ }^{123}$.

\section{RECAPITULACIÓN FINAL}

Cuanto se ha expuesto precedentemente, a nuestro modo de ver, contribuye a explicar el por qué ningún régimen francés, desde 1791, ha admitido la idea de un poder judicial que pudiera actuar como contrapeso del poder legislativo, salvaguardando la Constitución. Ciertamente, no han faltado en la historia constitucional francesa intentos de vertebrar un control judicial de constitucionalidad de las leyes, pero ninguno de ellos ha llegado a prosperar, pues no pueden en modo alguno considerarse como tales las experiencias que, particularmente, con las Constituciones de 1799 y 1852, se han dado de resultas de la creación de un Senado conservador que, supuestamente, estaba llamado a cumplir tal función de control.

diversas especies y posibilidades de salvaguardia de la Constitución), Tecnos, Madrid, 1983, pp. 11 y ss.; en concreto, p. 17.

120 Jean RIVERO: «Fin d’un absolutisme”, en Pouvoirs, núm. 13, 1980, pp. 5 y ss.; en concreto, p. 7.

121 Denis TALLON: "The Constitution and Courts in France", en The American Journal of Comparative Law, vol. XXVII, núm. 4, fall 1979, pp. 567 y ss.; en concreto, p. 567.

122 A. ESMEIN: Éléments de Droit Constitutionnel, tome premier, op. cit., p. 580.

123 A ello habría que unir, como peculiaridad muy particular, aunque en nada afecte al tema que nos ocupa, que la doctrina francesa ha salvado ciertas normas de algunas Constituciones, haciéndolas pervivir después del derrumbamiento del código constitucional. Paradigmático es el supuesto del artículo 75 de la Constitución del año VIII, que garantizaba a los agentes del Gobierno distintos de los Ministros, que no pudieran ser perseguidos por hechos relativos a sus funciones más que en virtud de una decisión del Consejo de Estado. Tal norma se mantendría en vigor bajo todos los regímenes posteriores hasta su derogación por un Decreto-ley de 19 de septiembre de 1870, del Gobierno de la Defensa Nacional. 
Las ideas-fuerza que se han expuesto, aunque no todas ellas tengan idéntico valor, han sido enormemente resistentes a toda innovación, teniendo algunas de ellas todavía hoy un peso específico en determinados sectores de la doctrina y entre la propia clase política, como ya se ha expuesto. Pero es inexcusable subrayar que no son tales ideas las únicas razones que explican el endémico rechazo al control judicial de constitucionalidad. La cabal comprensión del mismo exige atender a la situación existente en el Antiguo Régimen, que incluso, y como ya se anticipó, puede facilitarnos ciertas pistas para la mejor comprensión de algunos de los planteamientos de Montesquieu. Tal situación fue determinante de la configuración por los revolucionarios del poder judicial.

ABstract. The endemic refusal of the judicial review in France is the outcome of the conjuction of several principles. These ones have lasted all time long. The parliamentary sovereignty, the law's fetishism, the rigidity of the separation of powers's principle and the government by judiciary are some of them. Those force-ideas have extremely been resistant in front of any innovation. 